\title{
ZMIENNA TRWAŁOŚĆ DZIEŁA - PROBLEM PAMIĘCI SZTUKI MEDIÓW W KONTEKŚCIE WYSTAWY REINKARNACJA SZTUKI MEDIÓW
}

\author{
Variable Durability of a Work of Art - The Problem of Media Art Memory \\ in the Context of the Exhibition 'Reincarnation of Media Art'
}

\begin{abstract}
This text focuses on the memory of media art. The case study of Reincarnation of Media Art WRO exhibition from 2019 - "a unique exhibition about preserving media art and making its essence available" - is introduced by the author to discuss the life-cycle of time-based media artworks. Aforementioned case study is used as the basis for further discussion about "permanence through change" approach in preserving media art.
\end{abstract}

Keywords: media art, Nam June Paik, WRO Art Center, remediation, memory, trace, changeability, documentation

„Dzieto martwe to dzieło zapomniane”. Łukasz Szałankiewicz (Zenial) ${ }^{1}$

Reinkarnacja sztuki mediów to tytuł wystawy powstałej w kooperacji Centrum Sztuki WRO z japońską organizacją YCAM (Centrum Sztuki i Mediów Yamaguchi) i prezentowanej w ramach jubileuszowej edycji Biennale Sztuki Mediów WRO 2019 w trzydziestolecie

Wywiad z artystą, wyświetlany na ścianie galerii WRO w ramach wystawy. jego istnienia. Wystawa przyjęła funkcję mauzoleum sztuki mediów, prezentując „martwe” prace artystów współpracujących z obiema instytucjami ${ }^{2}$. Ciemną

2 Wystawę pokazano w dniach 15.05-29.09.2019 roku w Centrum Sztuki WRO we Wrocławiu. Była to druga odsłona wystawy, pierwotnie zorganizowanej z okazji piętnastolecia YCAM (Centrum Sztuki i Mediów Yamaguchi) przez grupę twórczą exonemo wraz z zespołem YCAM. Zob. http://wro2019.wrocenter.pl/ works/reincarnation-of-media-art/ (dostęp: 20.02.2020). 
przestrzeń galerii WRO, zaaranżowaną $\mathrm{w}$ formie kurhanu, wypełniły krypty grobowe zawierające osiem dzieł polskich i japońskich twórców, które ich zdaniem „straciły życie”3. Na ścianach wyświetlano zarejestrowane wcześniej wywiady z artystami, dotykające problemu (nie)trwałości sztuki mediów, które dopełniły narracją wystawę, stanowiąc ciekawe rozwinięcie poruszanych w jej ramach tematów. Wystawa problematyzowała kwestie żywotności dzieł medialnych, które w związku z małą odpornością na upływ czasu ulegają rozpadowi, pozostawiając po sobie zdezaktywowane ślady swego istnienia. Postęp techniczny, pojawiające się usterki wpływają niekorzystnie na funkcjonowanie dzieł opartych na technologii, wielokrotnie uniemożliwiając im sprawne działanie, co prowadzi bardzo często do swoistej ,śmierci dzieła”. Niektóre z klasycznych dzieł medialnych działają niepoprawnie bądź zniknęły bezpowrotnie, trafiając do obszaru tzw. martwych mediów (dead media $)^{4}$. Trudno przełożyć drobne subtelności, np. charakterystyczne dla dawnych systemów opóźnienia, związane z ograniczoną wydajnością ówczesnych procesorów komputerowych, trudno zrekonstruować nie tylko prace, ale też ich

Przewodnik audio po wystawie: https://soundcloud.com/user-634311404/reincarnation-of-media-art-przewodnik-audio-nowa-wersja (dostęp: 20.02.2020).

$4 \quad$ Sytuacja ta spotkała m.in. prace pionierki sztuki Internetu - Olii Lialiny. Zob. E. Wysocka, Wirtualne ciało sztuki. Ochrona i udostępnianie dziet audiowizualnych, Narodowe Centrum Kultury, Warszawa 2013. Por. B. Sterling, The DEAD MEDIA Project: A Modest Proposal and a Public Appeal, http://www.deadmedia.org/ modest-proposal.html (dostęp: 20.02.2020). percepcję. Znaczący postęp w zakresie transferu danych, problem automatycznego update'owania programów powoduja trudności z odtworzeniem takich samych lub podobnych funkcji realizowanych przez pionierskie dzieła. Wystawa Reinkarnacja sztuki mediów podnosi te kwestie, odnosząc je do szerszego problemu trwałości sztuki mediów, rozproszonej w wielości śladów pozostawionych na kruchej linii jej życia. Materialne szczątki prezentowanych dzieł stały się pretekstem do refleksji na temat pamięci rzeczy ${ }^{5}$, które zderzają ze sobą czasy i przestrzenie, pośrednicząc w doświadczeniu tego, co minione.

\section{Pamięć dzieła sztuki mediów}

„Trzeba podkreślić, że nie jest to ani malarstwo ani rzeźba tylko »sztuka czasu «" - pisał Nam June Paik do Rudolfa Jährlinga, właściciela Galerie Parnass, w której odbyła się pierwsza wystawa amerykańskiego artysty koreańskiego pochodzenia. Jego słowa pokazują przeobrażenia, jakie dokonały się w sztuce od końca lat 50. w podejściu do dzieła, które nie jest już statycznym obiektem kontemplacji, lecz procesem, komunikacją czy zmianą. Doświadczenia neoawangardy, posługującej się językiem performansu, happeningu, nowych technologii, wymu-

Zob. A. Zalewska, Rzecz, w: Modi memorandi. Leksykon kultury pamięci, red. M. Saryusz-Wolska, R. Traba, Wydawnictwo Naukowe Scholar, Warszawa 2014, s. 446-451.

6 Cyt. za: H.B. Hölling, Paik's Virtual Archive: Time, Change, and Materiality in Media Art, University of California Press, Oakland 2017, s. 109. Cytaty z dzieł obcojęzycznych w thumaczeniu autorki, chyba że zaznaczono inaczej. 
siły wyjście poza tradycyjne kategorie estetyczne i ponowne przemyślenie ich użyteczności w kontekście „sztuki czasu”. Procesualność dzieła wpłynęła na sposób jego prezentacji i doświadczenia, wymuszając zmiany w zakresie metod jego ochrony i konserwacji ${ }^{7}$. Wyrosła na gruncie tych przemian sztuka mediów różni się zasadniczo od tradycyjnych obiektów malarstwa czy rzeźby. Dzieło (time-based media) nie jest dłużej statycznym, unikalnym w swej jedności przedmiotem, lecz bardzo często to kolekcja komponentów technicznego sprzętu (hardware) i oprogramowania (software), które wspólnie budują odbiorcze doświadczenie. Postęp technologiczny zmienia status sztuki mediów, która aby przetrwać, podlega nieustannym przeobrażeniom, generując ogromną liczbę materiałów, dokumentacji, materialnych szczątków, które starają się zapobiec jej ulotności. W ten sposób dzieło sztuki staje się swoim własnym archiwum $^{8}$, ,akumulacją śladów własnej

W ostatnim czasie pojawiają się kolejne publikacje podejmujace temat przemian w polu konserwacji i ochrony sztuki mediów. Zob. Preserving and Exhibiting Media Art: Challenges and Perspectives, eds. J. Noordegraaf, C.G. Saba, B. Le Maître, V. Hediger, Amsterdam University Press, Amsterdam 2013; H.B. Hölling, Paik's Virtual Archive...; E. Wysocka, op. cit.; Digital Art through the Looking Glass: New Strategies for Archiving, Collecting and Preserving in Digital Humanities, eds. O. Grau, J. Hoth, E. Wandl-Vogt, Edition Donau-Universität, Krems 2019; Rethinking Curating: Art After New Media, eds. B. Graham, S. Cook, The MIT Press, Cambridge-London 2015.

8 Rozwinięcie tego wątku, zob. S. Szykowna, Między archiwum a baza danych - o doświadczeniu sztuki nowych mediów, ,Studia Europaea Gnesnensia” 2019, nr 19, s. 169-182. trajektorii",. W cyklu życia sztuka mediów generuje szczątki, zdezaktywowane ruiny, technologiczne relikty, stanowiące podstawę materialnej pamięci, magazynując informacje o tym, co było udziałem przeszłych pokoleń. Taką właśnie formę przyjęły umieszczone na wystawie w galerii WRO eksponaty. W jej ramach zaprezentowano osiem niesprawnych urządzeń, które niczym relikwie stały się nośnikiem pamięci dzieł, nośnikiem ich idei, która trwa mimo niedziałających hardware'ów. Wśród nich znalazły się: monitor kineskopowy, część Zen for $T V$ (1963) Nam June Paika; kaseta U-Matic Nam June Paika; telefon komórkowy używany w performansie Rafaela Lozano-Hemmera Amodal Suspension (2003); twardy dysk z danymi o pracy Web hopper (1996) Koichiro Eto; płytki obwodu drukowanego YMO Techno Badge (1980) Masakiego Fujihaty; stare iPhony z aplikacjami Nao Tokui (2008); taśmy VHS będące dokumentacją wideo performansu Ucieleśnianie (1994) Piotra Wyrzykowskiego; kaseta VHS z dokumentacja Performansu na życzenie (2001) Anny Płotnickiej i Pawła Janickiego; konsole Nintendo Gameboyzz Orchestra Project (2001); dyskietki zawierające kopie zapasowe plików tekstowych i korespondencji artystów Demosceny. Doświadczenie tego, co przeszłe, co minione, zdeponowane w niedziałającym sprzęcie, umieszczonym w grobowych kryptach, prowokuje do fundamentalnych pytań o życie i śmierć dzieła sztuki mediów. Material-

9 H.B. Hölling, The Archival Turn: Toward New Ways of Conceptualising Changeable Artworks, http://www.hannahoelling.com/wp-content/uploads/2016/09/The_Archival_Turn.pdf(dostęp: 20.02.2020). 
ność zgromadzonych na wystawie rzeczy uobecnia przeszłość w teraźniejszości, dając wgląd w to, co minione, lecz co opiera się zapomnieniu.

Wystawa Reinkarnacja sztuki mediów przywołuje pamięć tych dzieł na wiele różnych sposobów, pozwalając im trwać w odbiorczym doświadczeniu. Nie tylko poprzez zgromadzone szczątki dzieł, ich dokumentacje, ale także dzięki opowieści snutej w przewodniku audio, której odbiorca może wysłuchać, używając historycznych nośników dźwięku. Kulturową przestrzeń pamięci tworzą także transmitowane na ścianach galerii/mauzoleum wywiady $\mathrm{z}$ artystami wystawionych prac jak również informacje zebrane $\mathrm{z}$ udostępnionej w sieci ankiety, dotyczącej trwałości i przyszłości sztuki mediów ${ }^{10}$. To kolejny wymiar procesu pamiętania sztuki mediów, wspominania, odtwarzania przeszłości, który staje się jednocześnie jej wytwarzaniem. Mieke Bal mówi w tym kontekście o kulturowym pamiętaniu, które kładzie ,nacisk na aktywny, procesualny charakter pamięci jako tego, »co się robi« (act of memory, recall), w odróżnieniu od pamięci jako tego, »co się ma«"11. Przewodnik po wystawie,

10 Organizatorzy kierują do artystów następujące pytania: „Czy myślisz o długości życia twoich własnych dzieł? Zakładając, że możesz podróżować w czasie, w jaki sposób chciałbyś/ chciałabyś zastać swoje prace za 100 lat? Ponieważ istnieje wiele różnych definicji »śmierci« w kontekście istnienia człowieka, jak dokładnie zdefiniowałbyś/zdefiniowałabyś śmierć dzieła sztuki?". Zob. https://docs.google.com/forms/d/1seGoq2YGZoC5VsUHe7YC3yR-GXb8hJRqxb0gkTI0f2s/viewform?edit_requested=true (dostęp: 20.02.2020).

11 Z. Dziuban, Pamiętanie, w: Modi memorandi..., op. cit., s. 354. wywiady czy ankieta stają się w tym wypadku podejmowaną $\mathrm{w}$ teraźniejszości performatywną aktywnością, „w ramach której przeszłość jest nieustannie modyfikowania i przepisywana"12. Staje się przez to żywa i trwa dzięki kolejnym interpretacjom.

\section{Remediacje pamięci - Zen for TV Nam June Paika}

Wystawę w galerii WRO otwiera praca Zen for TV Nam June Paika, która w pionierski sposób wykorzystywała medium telewizji jako medium sztuki. Zaprezentowana podczas pierwszej wystawy artysty Exposition of Music - Electronic Television w 1963 roku w Galerie Parnass w Wuppertalu, doczekała się kilku wariantów realizacji z uwagi na różne modele telewizorów wykorzystanych od 1963 roku do jej stworzenia. Jeden z takich zużytych monitorów kineskopowych wykorzystanych w tym dziele umieszczono w grobowcu nr 00 wystawy Reinkarnacja sztuki mediów. W rzeczywistości były to niesprawne technicznie ,wnętrzności” dzieła, które zgodnie z instrukcjami artysty wymieniono na nowe w latach 2001-2002, a następnie umieszczono je w dawnej, oryginalnej obudowie monitora. Dość przewrotnie Zen for TV powstała $\mathrm{w}$ rezultacie uszkodzenia dwóch odbiorników telewizyjnych w trakcie transportu do galerii w Wuppertalu ${ }^{13}$.

\footnotetext{
Ibidem.

13 Pierwszy z uszkodzonych telewizorów został nazwany na cześć jego producenta Rembrandt Automatic, drugi - Zen for TV. W 1967 roku oryginalny odbiornik został zagubiony. Nam June Paik zrekonstruował dzieło dla kolekcjo-
} 
Transmitowana wskutek ich uszkodzenia pojedyncza horyzontalna linia stała się impulsem do twórczej reakcji artysty, który dzięki obróceniu kineskopu uzyskał wertykalny obraz, nawiązujący do zasad buddyzmu zen. Powstanie dzieła było więc reakcją na zaistniałą sytuację, nie zaś efektem długotrwałej pracy. Pojawiające się na przestrzeni czasu kolejne wersje Zen for TV Nam June Paika w doskonały sposób ilustrują proces remediacji, któremu podlegało dzieło. Opisane przez Jaya Davida Boltera i Richarda Grusina ${ }^{14}$ zjawisko pozwala lepiej zrozumieć procesy transformacji dzieł będące gwarancją ich przetrwania. Podejmowane działania dotyczą nie tylko medialnej translacji jednego formatu na drugi, ale także związanych z nią przekształceń czy transformacji wynikających z rekontekstualizacji i reinterpretacji zapożyczonych materiałów. Dokonujący się w ten sposób akt mediacji polega na zderzeniu ze sobą czasów, przestrzeni, swoistej pamięci źródła, która ożywa poprzez kolejne warianty realizacji. Strategia ta bliska jest artystycznej postawie Nam June Paika, zalecającego ulepszanie swoich dzieł, które muszą jego zdaniem iść „,W parze z postępem przemysłu" ${ }^{15}$. Artysta akceptował wpisaną w dzieło mediów zmien-

nera Wolfganga Hanha w 1975 roku. Obecnie jest ono częścią kolekcji MUMOK w Wiedniu, stało się także podstawą do stworzenia dwóch kolejnych replik. Zob. H.B. Hölling, Lost to Museum: Changing Media, Their Worlds, and Performance, „Museum History Journal” 2016, nr $9 / 2$.

14 J.D. Bolter, R. Grusin, Remediation: Understanding New Media, The MIT Press, Cambridge-London 2000.

15 Cyt. za: H.B. Hölling, Paik's Virtual Archive..., op. cit., s. 123. ność, podobnie jak awangardowi twórcy, otwierał sztukę na przypadek, rewidując uświęcone tradycją zasady tworzenia dzieł oparte na umiejętnościach artysty.

„Mój eksperymentalny telewizor nie jest zawsze interesujący, ale też nie zawsze jest nieinteresujący, podobnie jak przyroda, która jest piękna nie dlatego, że pięknie się zmienia, ale po prostu dlatego, że się zmienia"16. Słowa Nam June Paika świadczą o swoistej negacji niepowtarzalności dzieła sztuki mediów, jego oryginalności i akceptacji dla wszelkich zmian gwarantujących mu trwałość. Kolejne zremediowane wersje Zen for TV są kontynuacją pracy z 1963 roku, która trwając na przestrzeni czasu, ulega kolejnym transformacjom, zapewniającym jej pamięć w odbiorczym doświadczeniu. Dzieło Nam June Paika to dzisiaj zbiór różnych technicznych elementów wymienianych na przestrzeni czasu, kolejne warianty dzieła znajdujące się $\mathrm{w}$ rozsianych po całym świecie muzeach ${ }^{17}$, to w końcu instrukcja, powstała na prośbę Gilberta Silvermana, którą artysta dołączył do jednej z wersji, włączonej na stałe do kolekcji wpływowego patrona ruchu Fluxus:

16 N.J. Paik, Afterlude to the Exposition of Experimental Television, w: Theories and Documents of Contemporary Art: A Sourcebook of Artists' Writings, eds. K. Stiles, P. Selz, University of California Press, Berkeley-Los Angeles-London 1996, s. 494.

17 Zen for $T V$ wchodzi w skład kolekcji następujących instytucji: Smithsonian American Art Museum, Nationalgalerie Staatliche Museen w Berlinie, MUMOK (Museum moderner Kunst Stiftung Ludwig Wien) w Wiedniu, MoMA (Museum of Modern Art), SFoMA(San Francisco Museum of Modern Art). 
4/12 can be done - redone - in any new TV set.... [unreadable] as follows. Cut off vertical deflection unit and turn TV set 90 degree, dial on the bottom. There are two ways to cut off vertical unit 1 . Take off vertical output tube (jump the heater pins) OR 2. Keep all tubes and buy a similar deflection coil and connect the original deflection line to the new coil and waste the power there. 3. Anyway... [unreadable $]^{18}$.

Napisaną przez Paika instrukcję można uznać za konceptualny gest artysty, wpisujący się $\mathrm{w}$ tradycję ruchu Fluxus, którego był częścią, z drugiej zaś strony wyrażony językiem technicznym opis miał być swoistą gwarancją „przetrwania dzieła”, stając się z czasem śladem jego pamięci, wspomnieniem dawnej analogowej technologii, niemożliwej do odtworzenia $\mathrm{w}$ warunkach dzisiejszej cyfrowej telewizji transmitowanej na ekranach plazmowych czy LCD, które mimo umiejętności symulacji obrazu linii pozbawione są charakterystycznej dla odbiorników kineskopowych wewnętrznej logiki manipulowanych obwodów, ich mechanicznej specyficzności ${ }^{19}$. Zen for $T V$ nie da się zrekonstruować także z uwagi na niemożliwy do odtworzenia sygnał analogowy niemieckiej telewizji $\mathrm{z}$ lat 60 . XX wieku, kryjący się za wyświetlaną na ekranie pionową linią. Jak przekonuje Hanna Barbara Hölling, badaczka twórczości Nam June Paika, ,instrukcja pozbawia dzieło jego materialności, a jednocześnie zabezpiecza stabilność jego ciągłości. [...] Można stwierdzić, że obecność instrukcji jest indykatorem

18 Cyt. za: H.B. Hölling, Lost to Museum ..., s. 14. 19 Zob. ibidem. otwarcia dzieła na zmiany" ${ }^{\prime 20} . \mathrm{Z}$ drugiej jednak strony ta materialność dzieła z perspektywy pola sztuki pozostaje ciągle ważna. Wspomniana wyżej instrukcja została dołączona do konkretnej wersji Zen for $T V$, sygnowanej przez artystę numerem 4/12, umieszczonym na obudowie monitora. Ten powtórzony przez Paika gest Duchampa czyni z tego konkretnego odbiornika telewizyjnego, a raczej jego zewnętrznego korpusu, unikalny przedmiot, rodzaj „technicznego ready made"21, które - niepowtarzalne w swej materialności - wchodzi w muzealny obieg sztuki. Instrukcja wraz z kolejnymi niedziałającymi już podzespołami, kineskopami to „odciski”, ,resztki”, „znaki” Zen for TV, stanowiące formę jego kulturowego pamiętania, dzięki którym uobecnia się technologiczna przeszłość dzieła ${ }^{22}$.

\section{Strategie pamiętania}

„Prawdziwa śmierć oznaczałaby zniknięcie fizycznej formy, nagrań i ludzkich wspomnień. [...] Jeśli pozostaje choćby ułamek czegoś, nie uznałbym, że to coś odeszło całkowicie. Jeśli pozostat jakiś okruch, istnieje możliwość odtworzenia”.

Kazuhiko Hachiya ${ }^{23}$

20 H.B. Hölling, Sztuka i proces: kontynuacja, względny czas trwania $i$ archiwum Fluxus, w: Sztuka w procesie/proces w sztuce. Ku nowej filozofii ochrony dziedzictwa kultury, red. I. Szmelter, Akademia Sztuk Pięknych, Warszawa 2016, s. 56.

21 Ibidem, s. 14.

22 A. Zawadzki, Ślad, w: Modi memorandi..., op. cit., s. 470.

23 Wywiad $z$ artystą, wyświetlany na ścianie galerii WRO w ramach wystawy. 
Pytania o (nie)trwałość dzieł opartych na szybko starzejących się technologiach prowokują do dalszej refleksji na temat instytucjonalnych i artystycznych strategii pamiętania sztuki mediów. W obliczu rosnacej liczby prac opartych na czasie (time-based media) współczesne instytucje sztuki muszą nieustannie zmieniać się, dostosowując i wypracowując nowe procedury ich ochrony. W zależności od przyjętej strategii konserwacji dzieła sztuki mediów można mówić o paradygmacie wariabilności (variability) ${ }^{24}$ lub zmienności (changeability). Pierwszy z nich, wprowadzony do dyskursu teoretycznego przez Variable Media Network, odnosi się do praktyk zmierzających do zachowania określonych parametrów stałości pracy, transformacji dzieła, ale zgodnej $\mathrm{z}$ intencją jego twórcy, który określa warunki jego przyszłego trwania $^{25}$. Zmienność (changeability) z kolei, pojęcie wprowadzone przez Hannę Barbarę Hölling, ,dotyczy potencjału dzieła sztuki do zmiany, transformacji z jednego stanu w drugi. [...] może obejmować oczywiste zmiany fizyczne (znane z tradycyjnych mediów) oraz fundamentalne zmiany, które są ewidentne w historycznej praktyce (na przykład przejście filmu z aktywnej prezentacji do pasywnego reliktu)"26. W tym wypadku, zdaniem

24 Pojęcie wariabilności bliskie jest kategorii odtworzenia (re-creation), zaproponowanej przez Diego Mellado. Zob. D. Mellado, A Systems Engineer's Perspective for the Re-Creation of Media Art. n-Cha(n)-t by David Rokeby, w: Digital Art through the Looking Glass..., s. 180 .

25 http://www.variablemedia.net/e/welcome.html (dostęp: 20.02.2020).

26 H.B. Hölling, Sztuka i proces..., s. 56.
Hölling, konserwacja dzieła staje się raczej jego kontynuacją. Nie jest usilną i złudną próbą swoistego ,zamrażania dzieła sztuki w jednej preferowanej formie lub dążeniem do przywrócenia jego pierwotnego stanu"27, lecz implikuje różnice $^{28}$. Ten sposób rozumienia strategii ochrony prac medialnych okazuje się bliski idei wystawy we wrocławskim WRO, która nie proponuje nowych rozwiązań w zakresie praktyk i metod ich przetrwania, godząc się ze swoistą ,śmiercią" dzieł, brakiem możliwości odtworzenia, a tym samym ich pełnego doświadczenia. Akceptuje przemijalność, kruchość technologii i otwiera dzieło na zmianę, dopuszczając nowe możliwości odrodzenia się w innej formie, jego swoistej reinkarnacji. Umieszczone w grobowych kryptach obiekty stają się tym samym mediami pamięci ${ }^{29}$, które kumulują w sobie wiedzę o twórcach, czasie i miejscu powstania, chroniąc dzieło przed zapomnieniem. Jako media pamięci nie tylko utrwalają określoną wersję minionej rzeczywistości, ale też aktywnie ją (re)konstruują. Techniczne artefakty prezentowane w przestrzeni WRO metonimicznie odnoszą nas do prac, których nie da się już w pełni zrealizować. Wystawa ujawnia dzięki temu dynamiczną grę obecności i nieobecności, materialności i niematerialności, kryjącą się za doświadczeniem sztuki mediów.

\section{Ibidem.}

28 Eadem, The Archival Turn...

29 Zob. M. Pakier, M. Saryusz-Wolska, Media pamięci, w: Modi memorandi..., op. cit., s. 213-216. Zob. A. Erll, Kultura pamięci. Wprowadzenie, przeł. A. Teperek, Wydawnictwa Uniwersytetu Warszawskiego, Warszawa 2018. 
Część ze zgromadzonych w grobowych kryptach przedmiotów, takich jak popsuta kaseta U-Matic Nam June Paika, dyskietki Demosceny czy konsole Nintendo Gameboyzz Orchestra Project, zastygła $\mathrm{w}$ formie pasywnego reliktu, zdezaktywowanego przez upływ czasu. Inne z kolei jak podziurawiona kaseta VHS, będąca rejestracją performansu Piotra Wyrzykowskiego pt. Ucieleśnienie z 1994 roku stała się współczesną relikwią, upamiętniającą artystyczną interwencję, polegającą na nakłuwaniu w performatywnym geście taśmy i ciała artysty, który stygmatyzuje powstały w rezultacie film kroplami swojej krwi. Kolejne z prezentowanych dzieł istnieją dzięki ich dokumentacji. Taką formę przyjmuje performans Rafaela Lozano-Hemmera ${ }^{30}$ Amodal Suspension, zrealizowany w 2003 roku przy okazji otwarcia YCAM (Centrum Sztuki i Mediów Yamaguchi), zdeponowany w pierwszym grobowcu wrocławskiej wystawy. Wycinki prasowe, zdjęcia uczestników i telefon komórkowy wykorzystywany podczas wydarzenia są śladem interaktywnej instalacji, która umożliwiała uczestnikom przekształcanie wysyłanych przez nich wiadomości tekstowych w błyski reflektorów rozświetlających fasadę budynku YCAM. Lozano-Hemmer przykłada dużą wagę do dokumentacji wszystkich swoich prac, które mają własne strony internetowe, gdzie artysta umieszcza zdjęcia, filmy, opisy, bibliografie i instrukcje wraz z listą osób, które

30 Zob. R. Lozano-Hemmer, \#Best Practices for Conservation of Media Art from an Artist's Perspective, w: Digital Art through the Looking Glass..., op. cit. pracowały przy danym projekcie ${ }^{31}$. Realizowana przez niego bardzo przemyślana strategia przetrwania dzieł sztuki medialnej, ich swoistej kontynuacji zgodnej z wizją twórcy, wiąże się z podjęciem określonych czynności zachowujących dzieło dla przyszłych pokoleń.

Odmienną postawę w stosunku do strategii pamiętania swoich prac reprezentuje z kolei Anna Płotnicka, która godzi się $\mathrm{z}$ upływem czasu, często destrukcyjnie wpływającym na dzieło. Ważniejsza od troski o przetrwanie okazuje się być teraźniejszość pracy, jej niepowtarzalne „tu i teraz”, które wiąże się z konkretnymi emocjami i przeżyciami jej odbiorców. Zdjęcia i kaseta VHS znajdujące się w grobowcu nr 6 stanowią dokumentację Performansu na życzenie, zrealizowanego we współpracy z Pawłem Janickim w 2001 roku, w ramach którego artystka stała się obiektem interwencji odbiorczej, podlegając zdalnej manipulacji i reagując na polecenia uczestników wydarzenia. Nowatorska na początku XXI wieku technologia streamingu wideo na żywo, wykorzystana w pracy Płotnickiej, współcześnie nie wzbudza większych emocji. Poza kontekstem swego czasu dzieło ulega przedawnieniu, ze względu na brak pełnego zrozumienia idei artystki popada w niebyt. Wywołane z przeszłości przez kuratorów wystawy Reinkarnacja sztuki mediów - odradza się, żyje dzięki wspomnieniom, zdjęciom i kasecie, która staje się medium jego pamięci. Doświadczenie dokumentacji jest w tym sensie zapośredniczonym ,tu i teraz” dzieł, umożliwiającym ich swoistą, ,reinkarnację”.

\footnotetext{
Zob. ibidem.
} 


\section{Zakończenie}

„[Reinkarnacja sztuki mediów] skupia się na myśleniu o ciagłości kultury poprzez śmierć dzieła" ${ }^{32}$. Słowa te najlepiej oddają ideę wystawy w Centrum Sztuki WRO, która dotyka problemu wytwarzania kulturowej pamięci. Prezentowane w jej ramach „martwe” dzieła sztuki mediów są materialnym śladem przeszłości, uobecnionej w niedziałającym sprzęcie, który ożywa $\mathrm{w}$ snutych $\mathrm{w}$ przestrzeni galerii opowieściach. Reinkarnacja sztuki mediów to wystawa, która problematyzowała kwestie życia i śmierci prac, prowokując szerszą dyskusję na temat konserwacji, ochrony dzieł sztuki, ich (nie)możliwej kontynuacji. Dotykała kluczowych zagadnień związanych z pamięcią i trwaniem dzieł, których „śmierć" otwiera nowe perspektywy rozważań dotyczących przyszłych, nieznanych jeszcze możliwości ich odrodzenia.

\section{Bibliografia}

Bolter J.D., Grusin R., Remediation. Understanding New Media, The MIT Press, Cambridge-London 2000.

Borzyszkowska-Szewczyk M., Kilka refleksji o dynamice i porzadku dyskursu pamięcioznawczego, „Studia Kulturoznawcze” 2017, nr 1(11).

Digital Art through the Looking Glass: New Strategies for Archiving, Collecting and Preserving in Digital Humanities, eds. O. Grau, J. Hoth, E. Wandl-Vogt, Edition Donau-Universität, Krems 2019.

32 Przewodnik audio po wystawie: https://soundcloud.com/user-634311404/reincarnation-of-media-art-przewodnik-audio-nowa-wersja (dostęp: 20.02.2020).
Erll A., Kultura pamięci. Wprowadzenie, red. M. Saryusz-Wolska, Wydawnictwa Uniwersytetu Warszawskiego, Warszawa 2018.

Hölling H.B., Lost to Museum: Changing Media, Their Worlds, and Performance, „Museum History Journal” 2016, nr 9/2.

Hölling H.B., Paik's Virtual Archive: Time, Change, and Materiality in Media Art, University of California Press, Oakland 2017.

Hölling H.B., Sztuka i proces: kontynuacja, względny czas trwania i archiwum Fluxus, w: Sztuka w procesie/proces $w$ sztuce. Ku nowej filozofii ochrony dziedzictwa kultu$r y$, red. I. Szmelter, Akademia Sztuk Pięknych, Warszawa 2016.

Hölling H.B., The Archival Turn: Toward New Ways of Conceptualising Changeable Artworks, http://www.hannahoelling.com/ wp-content/uploads/2016/09/The_Archival_Turn.pdf (dostęp: 20.02.2020).

http://wro2019.wrocenter.pl/works/reincarnation-of-media-art/ (dostęp: 20.02.2020).

http://www.variablemedia.net/e/welcome. html (dostęp: 20.02.2020).

Laurenson P., Emerging Institutional Models and Notions of Expertise for the Conservation of Time-based Media Works of Art, https://www.academia.edu/33313096/ Emerging_institutional_models_and_notions_of_expertise_for_the_conservation_of_time-based_media_works_of_art (dostęp: 20.02.2020).

Modi memorandi. Leksykon kultury pamięci, red. M. Saryusz-Wolska, R. Traba, Wydawnictwo Naukowe Scholar, Warszawa 2014.

New Collecting: Exhibiting and Audiences after New Media Art, ed. B. Graham, Routledge, London 2016.

Paik N.J., Afterlude to the Exposition of Experimental Television, w: Theories and Documents of Contemporary Art: A Sourcebook of Artists' Writings, eds. K. Stiles, P. Selz, University of California Press, Berkeley-Los Angeles-London 1996. 
Preserving and Exhibiting Media Art: Challenges and Perspectives, eds. J. Noordegraaf, C.G. Saba, B. Le Maître, V. Hediger, Amsterdam University Press, Amsterdam 2013.

Przewodnik audio po wystawie, https://soundcloud.com/user-634311404/reincarnation-of-media-art-przewodnik-audio-nowa-wersja (dostęp: 20.02.2020).

Rethinking Curating: Art After New Media, eds. B. Graham, S. Cook, The MIT Press, Cambridge-London 2015.
Sterling B., The DEAD MEDIA Project: A Modest Proposal and a Public Appeal, http://www.deadmedia.org/modest-proposal.html (dostęp: 20.02.2020).

Szykowna S., Między archiwum a baza danych - o doświadczeniu sztuki nowych mediów, „Studia Europaea Gnesnensia” 2019, nr 19, s. 169-182.

Wysocka E., Wirtualne ciało sztuki. Ochrona $i$ udostepnianie dziet audiowizualnych, Narodowe Centrum Kultury, Warszawa 2013. 